\title{
PROFIL ANTROPOMETRI ATLET SEPAKBOLA PROFESIONAL PADA MASA TRANSISI
}

\author{
Rizki Mulyawan \\ Fakultas Ilmu Keolahragaan Universitas Negeri Yogyakarta, Jl. Colombo No. 1, Karangmalang Depok, Sleman, \\ Yogyakarta, Indonesia \\ rizkimulyawan@uny.ac.id
}

\begin{abstract}
Abstrak
Ada beberapa tahapan bagi pemain sepakbola dalam menjalani kompetisi, yaitu masa persiapan, masa kompetisi utama dan masa transisi. Dari ketiga tahap tersebut, masa transisi sering diabaikan oleh para pemain sepakbola di Indonesia. Hal ini sangat fatal, kadang ada pula yang salah dalam mempersepsikan masa transisi. Pengambilan data menggambarkan bagaimana kondisi atlet sepakbola profesional khususnya yang berdomisili di kota Bandung selama masa transisi (jeda kompetisi). Diperoleh 8 pemain sepakbola professional yang berasal dari kota Bandung dan sedang dalam waktu jeda kompetisi. Pengambilan data menggunakan Omron HBF 375 Karada Scan Body Composition Monitor. Lemak di area bawah kulit yang ada di seluruh tubuh berada dalam kondisi normal pada seluruh subjek, kecuali pada bagian lengan dan kaki sekitar 37,50\% dari 8 subjek masuk dalam kategori tinggi lemak, 62,50\% masuk dalam kategori normal. Sementara itu, kondisi otot rangka secara keseluruhan berada dalam kategori normal $(100 \%)$. Jika dispesifikkan ke beberapa bagian tubuh, kondisi otot rangka di batang tubuh, dalam hal ini tubuh bagian atas, semua subjek kondisi otot rangkanya masih tergolong rendah (100\%), kemudian di bagian lengan kondisi otot rangka kategori tinggi (100\%) dan pada bagian kaki seluruh subjek memiliki kondisi otot rangka yang termasuk dalam kategori sangat tinggi (100\%), dapat diartikan kondisi kaki ditopang oleh proporsi otot yang kuat. Pengambilan data lainnya, yaitu kadar lemak, data menunjukkan bahwa 37,50\% dari jumlah subjek memiliki kadar lemak dengan kategori tinggi, dalam hal ini di atas normal, meskipun peningkatannya tidak melebih $20 \%$, sementara $62,50 \%$ subjek berada dalam kategori normal. Kemudian instrumen lainnya, yaitu lemak yang melindungi organ vital (visceral fat), seluruh subjek dikategorikan normal (100\%) dan indeks massa tubuh (BMI) pun berada dalam kategori normal (100\%). Secara keseluruhan bisa dikatakan semua subjek dalam keadaan normal. Terdapat beberapa instrumen yang harus diperbaiki subjek ketika masa transisi, terkait komposisi lemak secara keseluruhan dan kondisi otot rangka bagian atas tubuh Pengambilan data ini berguna untuk menentukan program apa yang akan dibuat selanjutnya dalam masa transisi dan menjelang persiapan kompetisi.
\end{abstract}

Kata kunci: Sepakbola, Masa Transisi, Antropometri

\section{ANTHROPOMETRY PROFILE OF PROFESSIONAL SOCCER ATHLETES IN THE TRANSITION PERIOD}

\begin{abstract}
There are several stages for soccer players in undergoing the competition, namely the preparation period, the main competition period and the transition period. Of the three stages, the transition period is often ignored by soccer players in Indonesia. This is fatal, sometimes there is wrong perception in transition period. Retrieval of data illustrates how the condition of professional soccer athletes, especially those who live in the city of Bandung during the transition period (competition break). Obtained 8 professional soccer players who came from Bandung and are on transition period (competition break). Data collectiong use Omron HBF 375 Karada Scan Body Composition Monitor. Subcutaneous fat in the whole body is in normal condition in all subjects, except in the arms and legs about $37.50 \%$ of 8 subjects included in the high-fat category, $62.50 \%$ included in the normal category. Meanwhile, the condition of skeletal muscle as a whole is in the normal category (100\%). If specified
\end{abstract}


to several parts of the body, skeletal muscle conditions in the trunk, in this case the upper body, all subjects with skeletal muscle conditions are still relatively low (100\%), then in the arm the skeletal muscle conditions are high category (100\%) and on feet have skeletal muscle conditions that are included in the very high category (100\%), it meant that the foot's condition is supported by the proportion of strong muscles. Another data collected, in the name of fat content as general in the body, data showed that $37.50 \%$ of the total subjects had high fat content, in this case above normal, although the increase did not exceed more than $20 \%$, while $62.50 \%$ subjects were in the normal category. Then other instruments, fat that protects vital organs (visceral fat), all subjects were categorized in normal (100\%) and body mass index (BMI) was in the normal category (100\%). Overall it can be said that data from all subjects are normal. There are several instruments that must be improved by the subject during the transition period, related to the overall fat composition and condition of upper body skeletal muscles. Data collection is useful to determine what programs will be made later in the transition period and preparation period.

Keywords: Football, Transition Period, Anthropometry

\section{PENDAHULUAN}

Cabang olahraga sepakbola termasuk ke dalam olahraga kelompok yang sangat diminati oleh masyarakat Indonesia. Jika berbicara prestasi sejauh ini peringkat Indonesia masih ada di papan bawah dunia, namun untuk kawasan Asia Tenggara, Indonesia masih bisa bersaing. Di kancah olahraga prestasi, sepakbola memiliki 3 siklus yang harus dilalui oleh setiap atletnya, yaitu masa persiapan, masa pertandingan utama dan masa transisi. Pada masa persiapan, pelatih membuat dan mengaplikasikan program latihan yang disesuaikan dengan kekurangan atletnya, lalu meningkatkan kemampuan atlet sampai pada tahap tertentu. Pada tahap pertandingan utama, kompetisi berjalan sangat ketat, dalam satu minggu kadang atlet bisa melakukan dua sampai tiga kali pertandingan. Setelah kompetisi selesai, atlet masuk ke dalam masa transisi, yang mana masa transisi di kompetisi sepakbola Indonesia dapat mencapai 3-4 bulan dikarenakan sistem kompetisi yang kurang baik.

Banyak atlet di Indonesia yang beranggapan masa transisi adalah masa istirahat total, penyataan ini jelas sangat keliru. Di lain pihak, adapula yang memang sadar akan profesinya sebagai atlet sehingga melakukan latihan rutin. Yang terpenting jangan sampai terjadi penurunan performa (detrained), karena akan butuh waktu lama untuk mengembalikan kebugaran ke keadaan semula (Harsono, 2015).

Dalam beberapa kesempatan, seringkali atlet melakukan aktivitas olahraga selain sepakbola untuk menghilangkan rasa jenuh. Namun memungkinkan terjadinya perubahan komposisi tubuh yang akan mengakibatkan berkurangnya kemampuan dalam beradaptasi pada bentuk latihan sepakbola nantinya (Mujika, 2000). Untuk mengetahui bagaimana kondisi yang terjadi pada atlet di masa transisi, maka studi ini dilakukan untuk memperoleh data akurat mengenai antropometri pemain sepakbola profesional Indonesia, agar dapat dijadikan evaluasi bagi para atlet untuk merubah pola hidupnya sebagai atlet sepakbola profesional selama masa transisi. Data yang diperoleh pun nantinya akan dapat menjadi dasar dalam menentukan program apa yang tepat untuk diaplikasikan pada masa transisi dan persiapan menghadapi kompetisi nantinya.

\section{METODE}

Metode survey dengan pengukuran untuk memperoleh data yang dibutuhkan. Studi ini merupakan penelitian deskriptif dalam menggambarkan kondisi para pemain sepakbola Indonesia yang berasal dari Bandung. Studi dibuat tanpa membandingkan atau menghubungkan variabel satu dengan yang lainnya. Subjek yang digunakan dalam penelitian ini berasal dari beberapa pemain sepakbola professional Liga Sepakbola Indonesia tahun 2019, memiliki domisili di kota Bandung dan sedang dalam masa transisi (jeda kompetisi). Diperoleh 
sebanyak 8 pemain sepakbola yang sukarela ikut dalam pengambilan data studi di waktu jeda antar musim (masa transisi).

\section{Instumen Penelitian}

Pada penelitian ini, terdapat beberapa komponen yang harus diukur untuk kemudian dilakukan pengambilan data. Pengambilan data menggunakan Omron HBF 375 Karada Scan Body Composition Monitor. Adapun komponen-komponen tersebut dapat dilihat pada gambar di bawah ini;

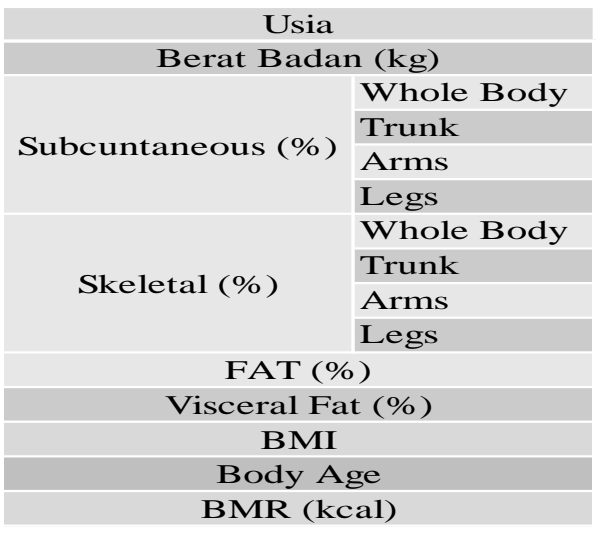

Gambar 1. Instrumen Penelitian

\section{Subcutaneous (Lemak di bawah kulit)}

Setiap orang terlahir dengan lemak yang ada di bawah kulit. Selain dari genetik, orang juga biasanya memiliki jumlah lemak di bawah kulit yang besar dikarenakan oleh makan lebih banyak kalori daripada kalori yang dibakar, memiliki sedikit massa otot, jarang melakukan aktivitas fisik, menderita diabetes, resistan terhadap insulin (Omron Healthcare, 2019).

\section{Skeletal Muscle (Otot Rangka)}

Skeletal muscle adalah tipe otot yang dapat kita lihat dan rasakan. Ketika melakukan work out untuk meningkatkan massa otot, skeletal muscle sedang dilatih. Skeletal muscle menempel pada tulang dan berpasangan - satu otot untuk menggerakkan tulang dalam satu arah dan otot lainnya untuk melakukan hal yang berlawanan. Meningkatkan skeletal muscle akan meningkatkan kebutuhan energy pada tubuh anda, Semakin banyak otot yang anda punya, semakin banyak kalori yang tubuh anda akan gunakan. Membentuk skeletal muscle dapat membantu mencegah penambahan berat badan yang terjadi secara drastic. Pemeliharaan dan peningkatan jumlah skeletal muscle erat hubungannya dengan angka metabolisme ketika sedang istirahat (Omron Healthcare, 2019).

Tabel 1. Kategori Skeletal Muscle

\begin{tabular}{|c|c|c|c|c|c|}
\hline Gender & Age & Low (-) & Normal (0) & High (+) & Very High (++) \\
\hline \multirow{4}{*}{ Female } & $\mathbf{1 8 - 3 9}$ & $<24.3$ & $24.3-30.3$ & $30.4-35.3$ & $\geqq 35.4$ \\
\cline { 2 - 6 } & $\mathbf{4 0 - 5 9}$ & $<24.1$ & $24.1-30.1$ & $30.2-35.1$ & $\geqq 35.2$ \\
\cline { 2 - 6 } & $\mathbf{6 0 - 8 0}$ & $<23.9$ & $23.9-29.9$ & $30.0-34.9$ & $\geqq 35.0$ \\
\hline \multirow{3}{*}{ Male } & $\mathbf{1 8 - 3 9}$ & $<33.3$ & $33.3-39.3$ & $39.4-44.0$ & $\geqq 44.1$ \\
\cline { 2 - 6 } & $\mathbf{4 0 - 5 9}$ & $<33.1$ & $33.1-39.1$ & $39.2-43.8$ & $\geqq 43.9$ \\
\cline { 2 - 6 } & $\mathbf{6 0 - 8 0}$ & $<32.9$ & $32.9-38.9$ & $39.0-43.6$ & $\geqq 43.7$ \\
\hline
\end{tabular}

Source: Omron Healthcare 


\section{Lemak Tubuh}

Lemak tubuh terdiri dari lemak tubuh esensial dan penyimpanan lemak. Lemak tubuh esensial ada pada jaringan saraf, susum tulang dan organ, dan kita tidak bias menghilangkan lemak ini tanpa adanya respon dari fungsi fisiologi. Penyimpanan lemak, di sisi lain, mewakili energy tambahan yang terakumulasi ketika energy dalam jumlah banyak dicerna dan berkurang ketika energy digunakan. Lemak tubuh esensial rata-rata sebanyak 3\% dari berat badan pada pria dan $12 \%$ dari berat badan pada wanita (Jeukendrup, 2019).

Tabel 2. Kategori Lemak di Dalam Tubuh

\begin{tabular}{|c|c|c|c|c|c|}
\hline Gender & Age & Low (-) & Normal (0) & High (+) & Very High (++) \\
\hline \multirow{3}{*}{ Female } & $\mathbf{2 0 - 3 9}$ & $<21.0$ & $21.0-32.9$ & $33.0-38.9$ & $\geqq 39.0$ \\
\cline { 2 - 6 } & $\mathbf{4 0 - 5 9}$ & $<23.0$ & $23.0-33.9$ & $34.0-39.9$ & $\geqq 40.0$ \\
\cline { 2 - 6 } & $\mathbf{6 0 - 7 9}$ & $<24.0$ & $24.0-35.9$ & $36.0-41.9$ & $\geqq 42.0$ \\
\hline \multirow{3}{*}{ Male } & $\mathbf{2 0 - 3 9}$ & $<8.0$ & $8.0-19.9$ & $20.0-24.9$ & $\geqq 25.0$ \\
\cline { 2 - 6 } & $\mathbf{4 0 - 5 9}$ & $<11.0$ & $11.0-21.9$ & $22.0-27.9$ & $\geqq 28.0$ \\
\cline { 2 - 6 } & $\mathbf{6 0 - 7 9}$ & $<13.0$ & $13.0-24.9$ & $25.0-29.9$ & $\geqq 30.0$ \\
\hline
\end{tabular}

Source: NIH/WHO guidelines for BMI

Source: Gallagher et al., American Journal of Clinical Nutrition, Vol. 72, Sept. 2000

\section{Visceral Fat}

Visceral fat dapat ditemukan di bagian abdomen dan melindungi organ vital. Visceral fat berbeda dengan lemak yang ada dibawah kulit, yang mana biasa disebut subcuntaneous fat. Visceral fat dapat membesar ataupun melebar tanpa bisa diketahui, karena tidak bisa dilihat dengan mata tertutup. Satu-satunya cara untuk melihat visceral fat hanya melalui Magnetic Resonance Imaging (MRI). Terlalu banyak kandungan visceral fat dalam tubuh akan memicu meningkatnya kadar lemak pada aliran darah, yang akan menyebabkan kondisi seperti tinggi kolesterol, penyakit jantung dan diabetes tipe 2 . Untuk mencegar terjadinya peningkatan kadarnya, sangat penting untuk mencoba mengurangi kadar visceral fat ke level normal. Perlu diketahui bahwa nilai visceral fat itu relatif, bukan bersifat mutlak (Omron Healthcare, 2019).

Tabel 3. Kategori Visceral Fat

\begin{tabular}{|c|c|}
\hline Visceral fat & Level Classification \\
\hline $1-9$ & 0 (Normal) \\
\hline $10-14$ & + (Tinggi) \\
\hline $15-30$ & ++ (Sangat Tinggi) \\
\hline
\end{tabular}

\section{Body Mass Index (BMI)}

Body Mass Index (BMI) atau Indeks Massa Tubuh adalah angka yang keluar hasil kalkulasi dari berat badan dan tinggi badan seseorang. BMI adalah indicator yang reliabilitas nya sudah teruji untuk mengukur kegemukan badan. BMI tidak menghitung lemak secara langsung, tapi penelitian menunjukkan bahwa BMI berhubungan dengan pengukuran lemak secara langsung pada tubuh. BMI juga digunakan sebagai alat untuk mengidentifikasi masalah berat badan pada orang dewasa. BMI = Berat badan $(\mathrm{kg}) /$ (Tinggi badan dalam meter * Tinggi badan dalam meter) 
Berikut ini adalah Tabel Indeks Massa Tubuh (IMT) atau BMI berdasarkan Departemen Kesehatan RI.

Tabel 4. Kategori BMI

\begin{tabular}{|l|l|}
\hline Nilai BMI (IMT) & Kategori \\
\hline$<17,0$ & Kurus, Kekurangan berat badan berat \\
\hline $17,0-18,4$ & Kurus, Kekurangan berat badan ringan \\
\hline $18,5-25,0$ & Normal \\
\hline $25,1-27,0$ & Gemuk, Kelebihan berat badan tingkat ringan \\
\hline$>27$ & Gemuk, Kelebihan berat badan tingkat berat \\
\hline
\end{tabular}

\section{Body Age}

Body Age (Usia tubuh) dapat diartikan sebagai estimasi pembanding kondisi tubuh dengan usia sebenarnya. Meskipun angka yang dikeluarkan berguna sebagai gambaran, namun dapat membantu dalam memberikan informasi bagaimana gambaran dalam tubuh kita.

\section{Basal Metabolic Rate (BMR)}

Basal Metabolic Rate (BMR) adalah energi yang dibutuhkan menjaga agar organ vital tetap bekerja pada saat keadaan istirahat. Energy yang digunakan untuk proses mempertahankan hidup di dalam tubuh seperti mempertahankan denyut jantun, temperature, sirkulasi darah, fungsi saraf dan bernafas. Kondisi BMR tiap orang akan berbeda-beda tidak dapat disamakan satu dengan yang lain. BMR dipengaruhi oleh usia, jenis kelamin, massa otot, hormone, kafein, stress, latihan dan pembatasan kalori.

\section{HASIL DAN PEMBAHASAN}

Gambaran komponen antropometri yang diperoleh pada subjek dideskeripsikan sesuai dengan instrument-instrumen penelitian yang sudah tertera seperti usia, berat badan $(\mathrm{kg})$, presentase lemak di bawah kulit (subcutaneous), presentase tulang (skeletal), presentase lemak, presentase lemak yang melindungi organ vital (visceral fat), BMI, body age, dan BMR.

Usia

Rata-rata usia dari 8 subjek adalah 27,38 tahun. Semua subjek berada di usia puncak performa di dunia sepakbola.

Tabel 5. Rerata Usia Subjek

\begin{tabular}{|l|r|r|r|r|r|r|r|r|c|}
\hline Nama & $\mathbf{1}$ & $\mathbf{2}$ & $\mathbf{3}$ & $\mathbf{4}$ & $\mathbf{5}$ & $\mathbf{6}$ & $\mathbf{7}$ & $\mathbf{8}$ & AVERAGE \\
\hline Usia & 25 & 30 & 26 & 28 & 29 & 25 & 27 & 29 & 27.38 \\
\hline
\end{tabular}

\section{Berat badan}

Tabel 6. Rerata Berat Badan Subjek

\begin{tabular}{|l|r|r|r|r|r|r|r|r|r|}
\hline Nama & $\mathbf{1}$ & $\mathbf{2}$ & $\mathbf{3}$ & $\mathbf{4}$ & $\mathbf{5}$ & $\mathbf{6}$ & $\mathbf{7}$ & $\mathbf{8}$ & AVERAGE \\
\hline $\begin{array}{l}\text { Berat } \\
\text { Badan } \\
\text { (kg) }\end{array}$ & 67.3 & 68.9 & 63.7 & 67 & 68.8 & 71.7 & 69.8 & 62.8 & 67.50 \\
\hline
\end{tabular}


MEDIKORA, Vol. XVIII No. 1 April 2019 - 22

Rizki Mulyawan

\section{Subcuntaneous (Lemak di Bawah Kulit)}

Tabel 7. Kategori Lemak di Bawah Kulit di Seluruh Tubuh

\begin{tabular}{|c|c|c|}
\hline \multicolumn{3}{|c|}{ SUBCUNTANEOUS } \\
\hline \multicolumn{3}{|c|}{ Seluruh Tubuh } \\
\hline Kategori & Jumlah & Presentase \\
\hline Rendah (-) & 0 & 0 \\
\hline Normal (0) & 8 & $100 \%$ \\
\hline Tinggi (+) & 0 & 0 \\
\hline Sangat tinggi (++) & 0 & 0 \\
\hline Total & 8 & $100 \%$ \\
\hline
\end{tabular}

Tabel 8. Kategori Lemak di Bawah Kulit pada Batang Tubuh (trunk)

\begin{tabular}{|c|c|c|}
\hline \multicolumn{3}{|c|}{ SUBCUNTANEOUS } \\
\hline \multicolumn{3}{|c|}{ Batang Tubuh (Trunk) } \\
\hline Kategori & Jumlah & Presentase \\
\hline Rendah (-) & 0 & 0 \\
\hline Normal (0) & 8 & $100 \%$ \\
\hline Tinggi (+) & 0 & 0 \\
\hline Sangat tinggi (++) & 0 & 0 \\
\hline Total & 8 & $100 \%$ \\
\hline
\end{tabular}

Tabel 9. Kategori Lemak di Bawah Kulit pada Bagian Lengan

\begin{tabular}{|c|c|c|}
\hline \multicolumn{3}{|c|}{ SUBCUNTANEOUS } \\
\hline \multicolumn{3}{|c|}{ Tangan } \\
\hline Kategori & Jumlah & Presentase \\
\hline Rendah (-) & 0 & 0 \\
\hline Normal (0) & 5 & $62.50 \%$ \\
\hline Tinggi (+) & 3 & $37.50 \%$ \\
\hline Sangat tinggi (++) & 0 & 0 \\
\hline Total & 8 & $100 \%$ \\
\hline
\end{tabular}

Tabel 10. Kategori Lemak di Bawah Kulit pada Bagian Kaki

\begin{tabular}{|c|c|c|}
\hline \multicolumn{3}{|c|}{ SUBCUNTANEOUS } \\
\hline \multicolumn{3}{|c|}{ Kaki } \\
\hline Kategori & Jumlah & Presentase \\
\hline Rendah (-) & 0 & 0 \\
\hline Normal (0) & 5 & $62.50 \%$ \\
\hline Tinggi (+) & 3 & $37.50 \%$ \\
\hline Sangat tinggi (++) & 0 & 0 \\
\hline Total & 8 & $100 \%$ \\
\hline
\end{tabular}


MEDIKORA, Vol. XVIII No. 1 April 2019 - 23

Rizki Mulyawan

Skeletal Muscle (Otot Rangka)

Tabel 11. Kondisi Otot Rangka Subjek Secara Keseluruhan

\begin{tabular}{|l|c|c|}
\hline \multicolumn{3}{|c|}{ SKELETAL } \\
\hline \multicolumn{3}{|c|}{ Seluruh Tubuh } \\
\hline Kategori & Jumlah & Presentase \\
\hline Rendah (-) & 0 & 0 \\
\hline Normal (0) & 8 & $100 \%$ \\
\hline Tinggi (+) & 0 & 0 \\
\hline Sangat tinggi (++) & 0 & 0 \\
\hline Total & 8 & $100 \%$ \\
\hline
\end{tabular}

Tabel 12. Kategori Kondisi Otot Rangka pada Batang Tubuh (Trunk)

\begin{tabular}{|c|c|c|}
\hline \multicolumn{3}{|c|}{ SKELETAL } \\
\hline \multicolumn{3}{|c|}{ Batang Tubuh (Trunk) } \\
\hline Kategori & Jumlah & Presentase \\
\hline Rendah (-) & 8 & $100 \%$ \\
\hline Normal (0) & 0 & 0 \\
\hline Tinggi (+) & 0 & 0 \\
\hline Sangat tinggi (++) & 0 & 0 \\
\hline Total & 8 & $100 \%$ \\
\hline
\end{tabular}

Tabel 13. Kategori Kondisi Otot Rangka pada Bagian Lengan

\begin{tabular}{|l|l|l|}
\hline \multicolumn{3}{|c|}{ SKELETAL } \\
\hline \multicolumn{3}{|c|}{ Tangan } \\
\hline Kategori & Jumlah & Presentase \\
\hline Rendah (-) & 0 & 0 \\
\hline Normal (0) & 0 & 0 \\
\hline Tinggi (+) & 8 & $100 \%$ \\
\hline Sangat tinggi (++) & 0 & 0 \\
\hline Total & 8 & $100 \%$ \\
\hline
\end{tabular}

Tabel 14. Kategori Kondisi Otot Rangka pada Bagian Kaki

\begin{tabular}{|c|c|c|}
\hline \multicolumn{3}{|c|}{ SKELETAL } \\
\hline \multicolumn{3}{|c|}{ Kaki } \\
\hline Kategori & Jumlah & Presentase \\
\hline Rendah (-) & 0 & 0 \\
\hline Normal (0) & 0 & 0 \\
\hline Tinggi (+) & 0 & 0 \\
\hline Sangat tinggi (++) & 8 & $100 \%$ \\
\hline Total & 8 & $100 \%$ \\
\hline
\end{tabular}


MEDIKORA, Vol. XVIII No. 1 April 2019 - 24

Rizki Mulyawan

\section{Lemak}

Tabel 15. Kategori Lemak di Seluruh Tubuh

\begin{tabular}{|c|c|c|}
\hline \multicolumn{3}{|c|}{ LEMAK KESELURUHAN } \\
\hline Kategori & Jumlah & Presentase \\
\hline Rendah (-) & 0 & 0 \\
\hline Normal (0) & 5 & $62.50 \%$ \\
\hline Tinggi (+) & 3 & $37.50 \%$ \\
\hline Sangat tinggi (++) & 0 & 0 \\
\hline Total & 8 & $100 \%$ \\
\hline
\end{tabular}

Visceral Fat

Tabel 16. Kategori Visceral Fat di Seluruh Tubuh

\begin{tabular}{|c|c|c|}
\hline \multicolumn{3}{|c|}{ VISCERAL FAT } \\
\hline Kategori & Jumlah & Presentase \\
\hline Normal (0) & 8 & $100 \%$ \\
\hline Tinggi (+) & 0 & 0 \\
\hline Sangat tinggi (++) & 0 & 0 \\
\hline Total & 8 & $100 \%$ \\
\hline
\end{tabular}

Body Mass Index (BMI)

Tabel 17. Kategori BMI

\begin{tabular}{|c|c|c|}
\hline \multicolumn{3}{|c|}{ BMI } \\
\hline Kategori & Jumlah & Presentase \\
\hline Sangat Kurus (- -) & 0 & 0 \\
\hline Kurus (-) & 0 & 0 \\
\hline Normal (0) & 8 & $100.00 \%$ \\
\hline Gemuk (+) & 0 & 0 \\
\hline Sangat gemuk (++) & 0 & 0 \\
\hline Total & 8 & $100 \%$ \\
\hline
\end{tabular}

Body Age

Tabel 18. Data Usia dan Body Age

\begin{tabular}{|l|l|l|l|l|l|l|l|l|c|}
\hline Nama & $\mathbf{1}$ & $\mathbf{2}$ & $\mathbf{3}$ & $\mathbf{4}$ & $\mathbf{5}$ & $\mathbf{6}$ & $\mathbf{7}$ & $\mathbf{8}$ & AVERAGE \\
\hline Usia & 25 & 30 & 26 & 28 & 29 & 25 & 27 & 29 & 27.38 \\
\hline Body Age & 31 & 34 & 30 & 30 & 32 & 33 & 30 & 28 & 31.00 \\
\hline
\end{tabular}

Basal Metabolic Rate (BMR)

Tabel 19. Data BMR

\begin{tabular}{|l|l|l|l|l|l|l|l|l|r|}
\hline Name & $\mathbf{1}$ & $\mathbf{2}$ & $\mathbf{3}$ & $\mathbf{4}$ & $\mathbf{5}$ & $\mathbf{6}$ & $\mathbf{7}$ & $\mathbf{8}$ & AVERAGE \\
\hline $\begin{array}{r}\text { BMR } \\
\text { (kcal) }\end{array}$ & 1576 & 1602 & 1515 & 1595 & 1620 & 1664 & 1643 & 1520 & 1591.88 \\
\hline
\end{tabular}




\section{MEDIKORA, Vol. XVIII No. 1 April 2019 - 25}

Rizki Mulyawan

\section{PEMBAHASAN}

Masa transisi biasanya kurang lebih berkisar antara 4 - 6 minggu (Silva et al., 2015), Meskipun di Indonesia kadang bisa mencapai 3-4 bulan (Harsono, 2015) dikarenakan sistem kompetisi yang belum bisa dikatakan baik. Di Indonesia, tanggal penyelenggaraan kompetisi terkadang disesuaikan dengan keinginan sponsor, tidak disesuaikan dengan periodisasi selama satu tahun. Sehingga masa jeda antar musim membuat atlet banyak yang hanya beristirahat, melakukan aktivitas fisik sekedar berkeringat, dll. Menyebabkan kualitas kemampuan pribadi pun menjadi menurun.

Terbukti dengan data yang diperoleh pada penelitian ini menunjukkan bahwa kadar lemak yang masuk dalam kategori tinggi pada beberapa pemain. Padahal presentase lemak tubuh termasuk parameter penting yang akan mempengaruhi performa. Pemain sepakbola dengan presentase lemak tubuh yang tinggi, juga dengan massa tubuh yang ekstra atau bertambah, mengalami kesulitan untuk mencapai kebutuhan dalam pertandingan dan sesi latihan, yang mana memerlukan perubahan yang sering antara sistem aerobik dan anaerobik (White et al., 1988).

Literatur mendukung pernyataan bahwa presentasi lemak tubuh pada atlet elit dapat bertambah sampai 20\% diantar musim, dalam hal ini masa transisi (Reilly, 1994; Shephard, 1999), dan dapat berkurang sampai kurang lebih 10\% selama musim kompetisi (Mangine et al., 1990; Shephard, 1999). Hal ini sesuai dengan data dan mengindikasikan bahwa atlet tidak menjaga kebugarannya dengan baik. Yang seharusnya dilakukan oleh atlet adalah melakukan penurunan intensitas latihan terlebih dahulu setelah selesai kompetisi dibarengi dengan penambahan volume latihan secara perlahan, karena studi menjelaskan bahwa penurunan dalam latihan selama masa transisi berpengaruh besar terhadap aspek fisiologi dan pengukuran performa (Silva et al., 2015).

Pengambilan data ini dilakukan untuk memberikan pemahaman bahwa adanya kesempatan bagi atlet untuk melakukan pemulihan (recovery) dan mempersiapkan diri untuk mengawali kompetisi berikutnya, maka klub, atlet dan bagian klinis harus mempertimbangkan menu latihan yang sifatnya individual untuk masa transisi (Silva et al., 2015) berdasar pada hasil pengambilan data yang sudah dilakukan. Oleh karena itu, pentingnya pengambilan data saat jeda kompetisi akan memudahkan pelatih mengetahui kondisi atlet dan memutuskan langkah yang harus dipilih dalam membuat program latihan.

\section{KESIMPULAN}

Secara keseluruhan, komponen antropometri berada dalam kondisi normal. Namun bagian tubuh yang masih perlu untuk ditingkatkan adalah pada bagian otot rangka (skeletal muscle) khususnya di bagian batang tubuh (trunk) atau bisa disebut bagian tubuh bagian atas. Peran otot rangka bagian atas dalam sepakbola sangat penting namun yang diperoleh dari pengambilan data ini justru menjadi kelemahan para atlet. Di sisi lain, beberapa atlet mengalami peningkatan kadar lemak meskipun tidak dalam jumlah yang besar, namun hal tersebut harus dibenahi dengan program latihan yang sesuai dengan kebutuhan atlet.

\section{SIMPULAN}

Simpulan tidak sekadar mengulangi data, tetapi berupa substansi pemaknaan. Dapat berupa pernyataan tentang apa yang diharapkan, sebagaimana dinyatakan dalam bab "Pendahuluan" yang akhirnya dapat menghasilkan bab "Hasil dan Pembahasan" sehingga ada kompatibilitas. Selain itu, dapat juga ditambahkan prospek pengembangan hasil penelitian dan prospek aplikasi penelitian selanjutnya ke depan (berdasarkan hasil dan pembahasan). 


\section{DAFTAR PUSTAKA}

Basal Metabolic Rate. Online: http://www.foodpyramid.com/basal-metabolic-rate/. Diakses 26/07/2019.

Harsono. (2015). Periodisasi Program Pelatihan. PT Remaja Rosdakarya Offset. Bandung.

Jeukendrup, A. \& Gleeson, M. (2019). Normal Ranges of Body Weight and Body Fat. Sport Nutrition 2nd Edition Ebook, Human Kinetics. Accessed by 07/26/2019.

Mangine, RE, Noyes, FR, Mullen, MP, and Barber, SD. (1990). A physiological profile of the elite soccer athlete. J Orthop Sport Phys Ther 12: 147-152,

Mujika I, Padilla S. (2000). Detraining: loss of training-induced physiological and performance adaptations. Part I: short term insufficient training stimulus. Sports Med. 30(2):79-87. 3.

Mujika I, Padilla S. (2000). Detraining: loss of training-induced physiological and performance adaptations. Part II: long term insufficient training stimulus. Sports Med. 30(3):145-54.

Omron Healthcare. Online: https://omronhealthcare.com/wp-content/uploads/hbf-510winstruction-manual.pdf. Diakses 26/07/2019

Reilly, T. Physiological profile of the player. (1994).In Football (Soccer) Ekblom, B, ed. London: Blackwell Scientific Publications, pp. 78-94.

Shephard, RJ. Biology and medicine of soccer: An update. J SportsSci 17: 757-786. 1999.

Silva, J. R., Akenhead, R., Brito, J., \& Nassis, G. (2015). The Transition Period in Soccer: A Window of Opportunity.

White, JE, Emery, TM, Kane, JL, Groves, R, and Risman, AB. (1998). Preseason fitness profiles of professional soccer players. In Science and Football. Reilly, T, Lees, A, Davids, K, and Murphy, WJ, eds. London: E \& FN Spon, pp. 164-171. 